\title{
Cash Transfer Programs and HIV-Related Outcomes: an Analysis of 42 Countries from
} 1996 to 2019

\author{
Aaron RICHTERMAN MD, ${ }^{1}$ Harsha THIRUMURTHY $\mathrm{PhD}^{2}$ \\ Running Title: Cash Transfers and HIV-Related Outcomes
}

Keywords: HIV, Cash Transfers, Poverty Reduction, Social Protection

\begin{abstract}
Abbreviations: CCT, Conditional cash transfer; CI, Confidence Interval; DHS, Demographic and Health Survey; IRR, incidence rate ratio; LMIC, low- and middle-income countries; OR, odds ratio; PEPFAR, President's Emergency Plan for AIDS Relief; UCT, unconditional cash transfer; UNAIDS, The Joint United Nations Programme on HIV/AIDS
\end{abstract}

\section{Word count: 4,699 \\ Number of references: 48 \\ Number of tables: 2 \\ Number of figures: 4}

Corresponding Author: Aaron Richterman, MD, MPH; Hospital of the University of Pennsylvania, 3400 Spruce Street, Philadelphia, PA 19104; e-mail: aaron.richterman@pennmedicine.upenn.edu telephone: 2674417915

${ }^{1}$ Division of Infectious Diseases, Hospital of the University of Pennsylvania, Philadelphia, PA, USA

${ }^{2}$ Department of Medical Ethics and Health Policy, University of Pennsylvania, Philadelphia, PA 


\section{Abstract}

\section{Background}

3 Many low- and middle-income countries have introduced cash transfer programs as part of their

4 poverty reduction and social protection strategies. These programs have the potential to

5 overcome various drivers of HIV risk behaviors and usage of HIV services, but their overall

6 effects on a broad range of HIV-related outcomes remains unknown.

\section{Methods}

8 We used publicly reported data to determine whether low- and middle-income countries with

9 HIV prevalence $>1 \%$ and baseline annual incidence $>1 / 1000$ had conditional or unconditional

10 cash transfer programs that covered $>5 \%$ of the impoverished population, and the year in which

11 those programs began and ended. We obtained country- and individual-level data on HIV-related

12 outcomes from UNAIDS and population-representative household surveys, focusing on the

13 period between 1996 and 2019. We conducted difference-in-differences analyses with country

14 and year fixed effects to evaluate the effects of cash transfer programs on country- and

15 individual-level HIV-related outcomes.

\section{Findings}

17 Forty-two countries across three continents were included. Among these, 21 were in the

18 intervention group, having implemented cash program(s) with impoverished population coverage

19 greater than 5\% during the study period. Cash transfer programs were associated with lower

20 probability of reporting sexually transmitted infection within the last 12 months among females

21 (odds ratio [OR] 0.67, 95\% confidence interval [CI] 0.50-0.91) and higher probability of an HIV 
medRxiv preprint doi: https://doi.org/10.1101/2021.12.16.21267921; this version posted December 17, 2021. The copyright holder for this preprint (which was not certified by peer review) is the author/funder, who has granted medRxiv a license to display the preprint in perpetuity. It is made available under a CC-BY-NC-ND 4.0 International license.

22 test within the last 12 months among females (OR 2.61, 95\% CI 1.15-5.88) and males (OR 3.19,

$2395 \%$ CI 2.45-4.15). For country-level outcomes, cash transfer programs were associated with a

24 reduction in new HIV infections (incidence rate ratio [IRR] 0.94, 95\% CI 0.89-0.99), but not

25 with the proportion of people with HIV receiving antiretroviral therapy $(5.0 \%, 95 \%$ CI $-0.2-10.1)$

26 or AIDS-related deaths (IRR 0.99, 95\% CI 0.95-1.03), though temporal analyses showed delayed

27 improvements in both antiretroviral coverage and deaths.

\section{Interpretations}

29 Cash transfer programs, which are being expanded in the context of the COVID-19 pandemic,

30 have the potential to promote ongoing efforts to end HIV as a public health threat. Alongside the

31 already existing focus on expanding biomedical services, these anti-poverty programs can play a

32 greater role in achieving global targets for HIV prevention and treatment.

\section{$33 \quad$ Funding}

34 None 


\section{Introduction}

36 HIV continues to be a major global public health threat, causing an estimated 1.7 million new

37 infections and 690,000 AIDS-related deaths in 2019. ${ }^{1}$ The Joint United Nations Programme on

38 HIV/AIDS (UNAIDS) Fast Track plan set the goal in 2014 of reducing annual infections to

39200,000 and AIDS-related deaths by $90 \%$ by $2030 .^{2}$ In addition to the rapid scaling up of clinical

40 services, the Fast Track plan also emphasizes the importance of expanding social protection for

41 achieving these objectives. ${ }^{3}$ Social protection is thought to be important because of the well-

42 documented relationship between poverty or economic inequality and risk factors for HIV

43 transmission (e.g., transactional sex among adolescent girls and young women, earlier age at

44 sexual debut, lower use of HIV services, and worse antiretroviral adherence) and HIV-related

45 morbidity and mortality. ${ }^{4-12}$

46 Over the past two decades, many low- and middle-income countries (LMICs) have introduced

47 cash transfer programs as central components of their poverty reduction and social protection

48 strategies. These programs, which range from conditional cash transfer (CCT) programs that are

49 common in Latin America to unconditional cash transfer (UCT) programs that are common in

50 sub-Saharan Africa, exist in over 100 LMICs, and many countries have expanded or introduced

51 new programs during the COVID-19 pandemic. A growing evidence base suggests that cash

52 transfer programs reduce poverty, foster economic autonomy, raise school attendance for

53 children, improve empowerment for women, and increase health service use, among other

54 benefits. ${ }^{13}$ Conceptually, cash transfer programs may improve outcomes by increasing income

55 and addressing economic barriers as well as by alleviating the psychological impacts of poverty

56 on mental bandwidth and decision-making. ${ }^{14-19}$ 
57 Despite the existence of cash transfer programs in many countries with generalized HIV

58 epidemics and the large number of evaluations of these programs, relatively few studies have

59 examined their effects on HIV-related outcomes at the individual or population level. Several

60 studies of predominantly smaller-scale cash transfer interventions have examined the direct

61 effects on beneficiaries and shown mixed but generally favorable changes in HIV-related

62 outcomes. For HIV prevention, a few randomized controlled trials of cash transfers have focused

63 on adolescent girls and young women. In Malawi, a cash transfer intervention for schooling

64 reduced HIV prevalence among schoolgirls. ${ }^{20}$ In South Africa, conditional cash transfers for

65 schooling had no effect on HIV incidence among adolescent girls and young women, although

66 the control group in this study received cash transfers and school attendance was high in both

67 study groups..$^{21}$ No randomized controlled trials have studied the impact of unconditional cash

68 transfer programs, which are more commonly used by governments in sub-Saharan Africa, on

69 HIV incidence. Non-experimental impact evaluations of the Kenyan government's cash transfer

70 program for caregivers of orphans and vulnerable children and another of the Malawi

71 government's household cash transfer program found delays in sexual debut. ${ }^{22,23}$ Finally, a much $^{2}$

72 larger literature has examined the effects of financial and non-financial incentives that are

73 tailored to specific HIV-related behaviors, but the incentive amounts are typically much smaller

74 than the size of cash transfers typically administered in LMICs. The typical magnitude of these

75 differences can be illustrated in Tanzania, where financial incentives conditional on HIV clinic

76 attendance were studied for six months in 2018 with a maximum total transfer of about $2 \%$ of

77 Gross Domestic Product (GDP) per capita, versus the national Productive Social Safety Net

78 Programme, which provides about $12 \%$ of GDP per capita annually to poor households. ${ }^{24,25}$

79 Studies of incentives have had mixed results, as some have demonstrated improvements in HIV 
80 testing uptake, ${ }^{26-29}$ retention in care ${ }^{25,30,31}$ adherence to antiretroviral therapy ${ }^{31-33}$ and virologic

81 suppression, ${ }^{25,34}$ while others have not. ${ }^{30,35-37}$ An evaluation of large-scale cash transfer programs

82 using cross population-level data from many different countries remains an important gap in the

83 literature. An advantage of using population-level data when evaluating cash transfer programs

84 (rather than using data from cash transfer beneficiaries alone) is that it will be possible to detect

85 spillover effects of cash transfers, especially if the transfers influence health behaviors that affect

86 the risk of HIV acquisition and transmission.

87 We hypothesized that larger, more generalized cash transfer programs might improve both

88 population and individual HIV-related outcomes. While national cash transfer programs in sub-

89 Saharan Africa are more commonly unconditional and less HIV-specific than those considered in

90 the studies described above, benefits may still be seen because of their more expansive reach and

91 spillover effects stemming from reduced HIV transmission. These national cash transfer

92 programs also tend to persist over time, compared to financial incentive or cash transfer studies

93 in which interventions have tended to be time limited.

94 However, few studies have evaluated the broader effects of large-scale cash transfer programs, a

95 policy-relevant topic given the burden of HIV and growing reliance on cash transfer programs.

96 To address this unanswered question, we conducted a difference-in-differences analysis

97 evaluating the effects of cash transfer programs on country- and individual-level outcomes in 42

98 countries with generalized HIV epidemics from 1996 to 2019.

\section{Methods}


medRxiv preprint doi: https://doi.org/10.1101/2021.12.16.21267921; this version posted December 17, 2021. The copyright holder for this preprint (which was not certified by peer review) is the author/funder, who has granted medRxiv a license to display the preprint in perpetuity.

It is made available under a CC-BY-NC-ND 4.0 International license .

100 We included all countries with HIV incidence greater than 1 per 1000 persons in 1996 and HIV

101 prevalence greater than $1 \%$ in at least one year between 1996 and 2019, ${ }^{1}$ a period when many

102 countries introduced cash transfer programs.

103 Data

104 We identified all major cash transfer programs within included countries. We manually searched

105 a variety of sources, detailed in the Supplementary Appendix, to identify the programs and

106 determine the year in which they were introduced, target population, whether they were

107 conditional or unconditional, amount of transfer, and the most recently available number of

108 beneficiaries. For each cash transfer program, we estimated the most recent impoverished

109 population coverage by dividing the total number of beneficiaries by the number of people living

110 below the international poverty line (Supplementary Appendix).

111 For individual-level data on HIV outcomes, we used the Demographic and Health Surveys

112 (DHS), which are nationally representative cross-sectional household surveys conducted every 5

113 years in many LMICs (Supplementary Appendix). Information was obtained for household and

114 individual characteristics for all female household members of reproductive age (15-49 years)

115 and a subset of males of reproductive age (typically $15-49,54$, or 59 years). We also used AIDS

116 Indicator Surveys (AIS), which are similar household surveys focused on HIV knowledge,

117 attitudes, behavior, and prevalence. We used DHS or AIS data from any country that met

118 eligibility criteria and any year between 1996 and 2019.

119 For country-level HIV statistics, we relied on UNAIDS annual estimates that are generated with

120 modeling techniques based on representative population-based surveys and surveillance studies. ${ }^{1}$

121 We obtained country and year UNAIDS estimates for the number of new HIV infections, the 
122 number of AIDS-related deaths, and proportion of people with HIV receiving antiretroviral

123 therapy.

124 We obtained additional time-varying covariates for each country and year that were likely to be

125 associated with changes in cash transfer programs and HIV outcomes: Gross Domestic Product

126 (GDP) per capita, ${ }^{38}$ President's Emergency Plan for AIDS Relief (PEPFAR) funding budgeted

127 per capita, ${ }^{39}$ The Global Fund to Fight AIDS, Tuberculosis and Malaria disbursements for HIV-

128 related programs per capita, ${ }^{40}$ and six Worldwide Governance Indicators from The World Bank

129 that are composite indicators based on 30 data sources: Voice and Accountability, Political

130 Stability and Absence of Violence, Government Effectiveness, Regulatory Quality, Rule of Law,

131 and Control of Corruption. ${ }^{38}$

132 Statistical Analysis

133 We performed difference-in-differences analyses using multivariable regression models to

134 compare trends in HIV-related outcomes in countries with cash transfer programs to those in the

135 same countries prior to cash transfer program introduction and to those in comparison countries

136 without cash transfer programs. Our analysis was developed based on a proposed causal

137 framework linking cash transfer programs to HIV-related outcomes, mediated through an effect

138 on poverty (Figure 1). Our primary explanatory variable of interest was a binary variable

139 indicating presence in a given year of a cash transfer program (or combination of programs) for

140 which the number of beneficiaries exceeded $5 \%$ of the population living below the poverty line

141 (Supplementary Appendix). ${ }^{38}$ Our choice of 5\% impoverished population coverage as the

142 threshold for our intervention group was subjective but chosen empirically as the smallest likely

143 coverage with which we might expect to see population effects. 
It is made available under a CC-BY-NC-ND 4.0 International license .

144 We examined the association between cash transfer programs and both individual- and country-

145 level outcomes. For individual-level outcomes, the unit of observation was a surveyed person in

146 a given country during a given year, and we stratified individual-level outcomes by sex.

147 Individual-level outcomes included the continuous variable age at sexual debut among youths

148 and the binary variables sexually transmitted infection within the prior 12 months, greater than

149 one sexual partner within the prior 12 months, HIV test within the prior 12 months, transactional

150 sex within the prior 12 months, and condom use during the last sexual encounter. The

151 transactional sex outcome was only analyzed for males because this question was only recently

152 added to the female questionnaire in the DHS and there were not enough observations for

153 meaningful comparisons.

154 For country-level outcomes, the unit of observation was the country-year. Country-level

155 outcomes included the number of new HIV infections, the number of AIDS-related deaths, and

156 the proportion of people with HIV receiving antiretroviral therapy.

157 We estimated linear regression models for continuous outcomes, logistic regression models for

158 binary outcomes, and negative binomial regression models for outcomes aggregated as counts.

159 We included fixed effects for each country, which adjusted for measured and unmeasured time-

160 invariant differences between countries, and for each year, which controlled for secular trends in

161 the outcomes across all countries. We used robust standard errors clustered at the country level.

162 For all outcomes, we included additional time-varying, country-level covariates of GDP per

163 capita, PEPFAR funding per capita, HIV-related disbursements by The Global Fund per capita,

164 and three World Bank Worldwide Governance Indicators (Control of Corruption, Political

165 Stability and Absence of Violence, and Voice and Accountability). The other three World Bank

166 Worldwide Governance Indicators (Government Effectiveness, Regulatory Quality, and Rule of 
medRxiv preprint doi: https://doi.org/10.1101/2021.12.16.21267921; this version posted December 17, 2021. The copyright holder for this preprint (which was not certified by peer review) is the author/funder, who has granted medRxiv a license to display the preprint in perpetuity.

It is made available under a CC-BY-NC-ND 4.0 International license .

167 Law) were not included because of collinearity (Supplementary Appendix). For individual-level

168 outcomes, we included additional covariates - age, single marital status, education, wealth

169 quintile, and rural/urban household setting - and used survey commands to apply sampling

170 probability weights.

171 We performed several secondary and sensitivity analyses to better characterize the association

172 between cash transfer programs and HIV-related outcomes. First, because country-level

173 outcomes were available annually, we evaluated the temporal relationship between cash transfer

174 programs and country-level outcomes by creating a series of binary indicators for each year after

175 the cash transfer period began. Second, we explored whether there were interactions between

176 cash transfer programs and having above-median HIV prevalence $(>3.7 \%)$ at the start of the cash

177 transfer program. Third, we did a similar interaction analysis based on whether a country's cash

178 transfer program had above-median coverage (>23\% of the population living below the poverty

179 line). Fourth, we stratified models for individual-level outcomes by wealth quintile. Fifth, while

180 our models controlled for PEPFAR and Global Fund spending, to further ensure there was no

181 major collinearity contributing to our findings we used PEPFAR funding per capita and HIV-

182 related Global Fund disbursements per capita as outcomes in our primary models to assess for

183 correlation with cash transfer programs. Sixth, we assessed whether individual countries might

184 be outliers for key outcomes by assessing whether estimates changed substantially after

185 excluding each individually.

186 The difference-in-differences design is quasi-experimental and relies on the parallel trends

187 assumption, which is that in the absence of the implementation of cash transfer programs, trends

188 in outcomes would be similar in the intervention and comparison countries. We tested whether

189 intervention and comparison countries had similar trends in the pre-cash transfer period by 
medRxiv preprint doi: https://doi.org/10.1101/2021.12.16.21267921; this version posted December 17, 2021. The copyright holder for this preprint (which was not certified by peer review) is the author/funder, who has granted medRxiv a license to display the preprint in perpetuity.

It is made available under a CC-BY-NC-ND 4.0 International license .

190 estimating regression models using only data prior to the cash transfer period in each country and

191 including an interaction term between an indicator of whether the country was in the intervention

192 group and a linear time trend. We tested the parallel trends assumption for outcomes with

193 significant findings in our primary analysis. We further evaluated pre-trends in the country-level

194 outcomes by including binary indicators for the four years prior to the cash transfer period in the

195 previously mentioned temporal analysis. Using a temporal analysis to visualize pre-trends for the

196 individual-level outcomes (which were measured in survey) is more difficult because annual

197 survey data were not available for countries. As a result, sample sizes vary greatly by year. We

198 attempted to mitigate this issue somewhat by categorizing multiple years together to allow for

199 greater interpretability, but temporal trends for the individual-level outcomes should be

200 interpreted with caution.

201 Recent advances in difference-in-differences analyses with variation in intervention timing have

202 shown that estimates may be biased particularly if there is heterogeneity in intervention effect

203 over time. ${ }^{41,42}$ We conducted a series of additional analyses to assess for the presence and

204 magnitude of this potential bias, ${ }^{43}$ detailed in the Supplementary Appendix.

205 Additional details on the regression models are available in the Supplementary Appendix. We

206 performed statistical analysis using SAS V.9.4 and R V.3.5.2 using the ggplot2 package.

207 Data Availability Statement

208 Analyzed data can be requested from the DHS program website

209 (https://www.dhsprogram.com/Data/) or are publicly available from UNAIDS

210 (http://aidsinfo.unaids.org/), The World Bank (https://data.worldbank.org/data-catalog/), 
medRxiv preprint doi: https://doi.org/10.1101/2021.12.16.21267921; this version posted December 17, 2021. The copyright holder for this preprint (which was not certified by peer review) is the author/funder, who has granted medRxiv a license to display the preprint in perpetuity.

It is made available under a CC-BY-NC-ND 4.0 International license .

211 PEPFAR (https://data.pepfar.gov/financial), and The Global Fund (https://data-

212 service.theglobalfund.org/downloads).

213 Code Availability Statement

214 Analysis code is available upon request to the corresponding author.

215 Role of the Funding Source

216 None

217 Results

218 Forty-two countries were eligible for inclusion in this study - $36(86 \%)$ in Africa, $4(10 \%)$ in

219 Latin America and the Caribbean, and 2 (5\%) in Asia (Table 1, Supplementary Figures 1-3).

220 Among these, 21 countries implemented an eligible cash transfer program (or combination of

221 cash transfer programs) at some point during the study period (Figure 1). In these countries, there

222 were 36 cash transfer programs - 28 were unconditional and eight were conditional

223 (Supplementary Table 1). The median total coverage level for cash transfer programs in the

224 intervention group was $23 \%$ of the impoverished population (IQR 14-63\%) and the median HIV

225 prevalence at the beginning of the cash transfer period was 3.7\% (IQR 1.5-10.7\%).

226 At the start of the study period, intervention countries had higher HIV prevalence (median $4.1 \%$

227 vs $1.7 \%$ ) and annual HIV incidence rate (median 3.8 vs 2.2 per 1,000 persons) relative to

228 comparison countries, but there was no difference between them in any of the six World Bank

229 Governance Indicators (Table 1). All countries received some HIV-related Global Fund 
medRxiv preprint doi: https://doi.org/10.1101/2021.12.16.21267921; this version posted December 17, 2021. The copyright holder for this preprint (which was not certified by peer review) is the author/funder, who has granted medRxiv a license to display the preprint in perpetuity.

It is made available under a CC-BY-NC-ND 4.0 International license .

230 disbursements during the study period, and $16(76 \%)$ intervention countries relative to $8(38 \%)$

231 control countries received PEPFAR funding at some point during the study period.

232 We obtained individual survey data from 99 DHS and 6 AIS conducted in included countries

233 during the study period - 24 during intervention years and 82 during comparison years (Figure

234 1). There were $1,885,733$ survey respondents in total, of whom $1,295,177(69 \%)$ were female

235 and 545,867 (29\%) were interviewed during intervention years (Supplementary Tables 4-6).

236 In our primary individual-level analyses, among females, cash transfer programs were associated

237 with a lower probability of having a sexually transmitted infection within the last 12 months

238 (odds ratio [OR] 0.67, 95\% confidence interval [CI] 0.50-0.91) and higher probability of having

239 had an HIV test within the last 12 months (OR 2.61, 95\% CI 1.15-5.88) (Table 2, Supplementary

240 Tables 7-17). PEPFAR funding per capita (OR 1.14 per $\$ 5$ increase, 95\% CI 1.01-1.30) and

241 HIV-related Global Fund disbursements per capita (OR 1.48 per $\$ 5$ increase, 95\% CI 1.18-1.84)

242 were also associated with an increased probability of having had an HIV test within 12 months.

243 Among males, cash transfer programs were significantly associated with an increased probability

244 of having an HIV test within the last 12 months (OR 3.19, 95\% CI 2.45-4.15) (Table 2,

245 Supplementary Tables 7-17). PEPFAR funding per capita (OR 1.22 per $\$ 5$ increase, 95\% CI

246 1.12-1.32) and HIV-related Global Fund disbursements per capita (OR 1.22 per \$5 increase, 95\%

247 CI 1.09-1.36) were also associated with an increased probability of having an HIV test within the

248 last 12 months.

249 In our primary country-level analyses, cash transfer programs were associated with a reduction in

250 new HIV infections (incidence rate ratio [IRR] 0.94, 95\% CI 0.89-0.99), but not with the

251 proportion of people with HIV receiving antiretroviral therapy $(5.0 \%, 95 \%$ CI $-0.2-10.1)$ or 
medRxiv preprint doi: https://doi.org/10.1101/2021.12.16.21267921; this version posted December 17, 2021. The copyright holder for this preprint (which was not certified by peer review) is the author/funder, who has granted medRxiv a license to display the preprint in perpetuity.

It is made available under a CC-BY-NC-ND 4.0 International license .

252 AIDS-related deaths (IRR 0.99, 95\% CI 0.95-1.03). In the same models, PEPFAR funding per

253 capita was associated with a reduction in AIDS-related deaths (IRR 0.98 per $\$ 5$ increase, $95 \%$ CI

254 0.97-0.99) and an increase in the proportion of people with HIV receiving antiretroviral therapy

255 (2.6\% per $\$ 5$ increase, 95\% CI 1.7-3.5), results that are consistent with an earlier analysis of the

256 relationship between PEPFAR and HIV outcomes. ${ }^{44}$ PEPFAR funding per capita was not

257 associated with new HIV infections (IRR 1.00 per \$5 increase, 95\% CI 0.99-1.01). In addition,

258 HIV-related Global Fund disbursements per capita were associated with an increase in the

259 proportion of people with HIV receiving antiretroviral therapy (3.3\% per $\$ 5$ increase, $95 \%$ CI

260 0.4-6.2), but not with new HIV infections (IRR 0.99 per $\$ 5$ increase, 95\% CI 0.98-1.00) or

261 AIDS-related deaths (IRR 0.99 per $\$ 5$ increase, 95\% CI 0.98-1.01).

262 We next evaluated associations between cash transfer programs and country-level outcomes over

263 time (Figure 2). In fully adjusted models, we found that new HIV infections were significantly

264 lower in the first year of the cash transfer program (IRR 0.94, 95\% CI 0.89-0.99). While the

265 effects on new infections became larger in subsequent years after the introduction of cash

266 transfer programs, they were less precisely estimated over time as a result of declining numbers

267 of observations and were no longer significant after the second year of the cash transfer program.

268 There were no significant changes in AIDS-related deaths during the first year of the cash

269 transfer program (IRR 0.99, 95\% CI 0.95-1.03), consistent with our primary analysis. However,

270 we found significant reductions in AIDS-related deaths by the second year of the cash transfer

271 program (IRR 0.91, 95\% CI 0.83-0.99), with larger reductions over time that peaked in the ninth

272 year of the cash transfer program (IRR $0.75,95 \%$ CI $0.57-0.99$ ). Similarly, there was no

273 significant change in the proportion of people with HIV receiving antiretroviral therapy on the 
274 first year of the cash transfer program $(0.8 \%, 95 \% \mathrm{CI}-1.0 \%-2.5 \%)$, but we found a significant

275 increase by the second year (3.0\%, 95\% CI 0.3-5.7), with larger increases over time.

276 In the interaction analysis, the effects of cash transfer programs were greater in higher

277 prevalence countries for the outcomes of an HIV test in the last 12 months among females

$278(\mathrm{p}<0.0001)$ and males $(\mathrm{p}<.0001)$, and in lower prevalence countries for new HIV infections

$279(\mathrm{p}=0.007)$ (Figure 3, Supplementary Table 21). The effects of cash transfer programs were

280 greater with higher coverage cash transfer programs for the outcomes of sexually transmitted

281 infection in the last 12 months among females ( $p<0.0001)$, having had an HIV test in the last 12

282 months among females $(\mathrm{p}=0.05)$ and males $(\mathrm{p}<.0001)$, and AIDS-related deaths $(\mathrm{p}=0.01)$.

283 When stratifying individual-level outcomes by wealth quintile, there were some modest trends

284 suggesting larger effects in poorer segments of the population, though these were inconsistent

285 and not definitively identified (Supplementary Figure 4). We confirmed that there was no

286 significant association between the presence of cash transfer programs and either PEPFAR

287 funding per capita or HIV-related Global Fund disbursements when these were included in our

288 primary model as outcomes (Supplementary Tables 22-23). Exclusion of individual countries did

289 not reveal possible outlier countries for any outcome except for HIV testing in females, for

290 which Guinea and Zambia were potentially outliers whose exclusion substantially changed the

291 estimated effect of cash transfers (Supplementary Tables 24-27).

292 Our fully adjusted models to test whether intervention and comparison countries had similar

293 trends in outcomes before the introduction of cash transfers in a given country showed no

294 differences between countries for the individual-level outcome of having a sexually transmitted

295 infection in the last 12 months for females (OR 0.98, 95\% CI 0.92-1.04) or males (OR 0.99, 95\% 
medRxiv preprint doi: https://doi.org/10.1101/2021.12.16.21267921; this version posted December 17, 2021. The copyright holder for this preprint (which was not certified by peer review) is the author/funder, who has granted medRxiv a license to display the preprint in perpetuity.

It is made available under a CC-BY-NC-ND 4.0 International license .

296 CI 0.95-1.02), or for the country-level outcome of new HIV infections (IRR 0.99, 95\% CI 0.96-

297 1.02) (Supplementary Tables 28-30). There were small, significant differences of opposite

298 magnitude in trends in outcomes before the introduction of cash transfers for the individual-level

299 outcome of having an HIV test within the prior 12 months for females (OR 0.81, 95\% CI 0.81-

300 0.82) and males (OR 1.27, OR 1.01-1.12) (Supplementary Tables 31-32). There were no

301 discernible differences in outcomes between intervention and control countries in the four years

302 prior to the cash transfer period in our temporal analysis of country-level (Figure 2) or

303 individual-level outcomes (Supplementary Figures 5-6) except for the HIV testing outcome

304 among males, where there was some visual evidence of differential pre-trends in cash transfer

305 countries.

306 Additional analyses suggested that the effect of cash transfers was heterogeneous over time but

307 that any resultant bias was likely small (Supplementary Appendix, Supplementary Figures 7-8,

308 Supplementary Tables 33-34).

309 Discussion

310 In this study of 42 countries with generalized HIV epidemics of varying magnitude across three

311 continents from 1996 to 2019, we found that sizeable cash transfer programs were associated

312 with important improvements in HIV-related outcomes at both the population and individual

313 levels. These included an immediate reduction in new HIV infections and delayed improvements

314 in both AIDS-related deaths and the proportion of people with HIV receiving antiretroviral

315 therapy, with benefits that grew larger over time. Among individuals, we found that cash transfer

316 programs were associated with a reduction in sexually transmitted infections (a key proxy

317 measure for risk of HIV transmission) among females, as well as large increases in recent HIV 
318 testing among males and females, though there were small differential pre-trends for the HIV

319 testing outcome so this finding should be interpreted with some caution. Our interaction analyses

320 showed that cash transfer programs with greater numbers of beneficiaries had the largest effects

321 on HIV-related outcomes, suggesting an element of dose-response at the population level. We

322 also found that the relationship between cash transfer programs and HIV testing was strongest in

323 countries with higher baseline HIV prevalence, indicating the importance of the specific context

324 of a given country's HIV epidemic. To our knowledge, this is the first study to have combined

325 data from all countries with generalized HIV epidemics and studied the effects of large-scale

326 cash transfer programs.

327 While our findings are consistent with prior evidence from randomized controlled trials of cash

328 transfer interventions that support the use of cash transfers for the prevention of HIV,,$^{20,45-47}$ and

329 along the HIV care continuum, ${ }^{25-34}$ there are several notable distinctions to consider when

330 interpreting our findings. First, the cash transfer programs considered in this study were

331 generally of larger scale and less HIV-specific than those studied in the randomized trials.

332 Second, almost all of the cash transfer interventions studied in randomized trials were

333 conditional on intermediary outcomes like school attendance, negative testing for sexually

334 transmitted infections, HIV testing, or clinical follow up, whereas nearly $80 \%$ of the programs

335 considered in our analysis were unconditional. Our study thus provides evidence, across many

336 countries with generalized HIV epidemics, on the effects of primarily government-led cash

337 transfer programs. Third, by evaluating outcomes for entire populations (i.e. by including

338 individuals and households that did not receive transfers), our findings also capture the indirect

339 or spillover effects of these interventions. These spillover effects are likely to be important in the 
340 context of an infectious disease with transmission dynamics and clinical outcomes that are

341 heavily influenced by structural factors like poverty and food insecurity.

342 There are a number of hypothesized mechanisms by which cash transfer interventions could

343 improve HIV-related outcomes. By increasing economic well-being, empowerment among

344 women, and educational attainment, cash transfers may lead to lower risk sexual behaviors (as

345 evidenced in our analysis by a reduction in sexually transmitted infections), thus lowering the

346 probability of acquiring or transmitting HIV. ${ }^{13}$ This plausibly includes a reduction in

347 transactional sex among women, ${ }^{48}$ an important driver of HIV risk among adolescent girls and

348 young women in particular for which data were unavailable to consider in our analysis. ${ }^{5}$ Cash

349 transfer programs may also lead to improvements along the HIV care continuum (i.e., HIV

350 testing, clinic attendance, and antiretroviral adherence) through a direct economic mechanism

351 that reduces barriers to care and a psychological mechanism that promotes health-seeking

352 behaviors through improvements in mental bandwidth. ${ }^{14}$ As a result, cash transfers may lead to

353 increases in HIV diagnoses (as evidenced in our analysis by increased HIV testing), engagement

354 in clinical care by people with HIV, and higher probability of receiving and adhering to

355 antiretroviral therapy with subsequent virologic suppression (as evidenced in our analysis by a

356 delayed increase in the proportion of people with HIV receiving antiretroviral therapy). This

357 would both directly improve clinical outcomes for people with HIV and reduce rates of

358 transmission because of the highly effective strategy of using HIV treatment as prevention,

359 commonly referred to as "Undetectable = Untransmittable" or "U=U." By supporting preventive

360 health behaviors, anti-poverty interventions like cash transfers can thus play an important role in

361 improving individual HIV outcomes and preventing HIV transmission by intervening proximally

362 to current efforts for HIV control, which are focused primarily at the health system level. 
363 While previous analyses have used a similar design to study effects of programs like PEPFAR,

364 this study is the first to do so for a common anti-poverty program that a growing number of

365 LMICs are introducing as central features of their poverty reduction and social protection

366 strategies. ${ }^{44}$ While not the primary objective of this study, our findings also suggest

367 improvements in HIV testing, population antiretroviral coverage, and AIDS-related deaths

368 related to PEPFAR and The Global Fund.

369 This study has several limitations. The cash transfer programs we considered were

370 heterogeneous in terms of target population, size of transfer, conditionality, and coverage. Due to

371 sample size limitations, we cannot precisely determine the relative importance of these other

372 features of cash transfer programs, although in our interaction analyses we do establish that

373 programs which covered more individuals tended to have larger effects. In particular, the relative

374 amount of the transfer is likely to influence any effect it has on health outcomes, but because of

375 variability of transfer size within many of the programs and inconsistent reporting we were

376 unable to meaningfully consider this in our analysis. While the DHS and AIS surveys do not

377 uniformly indicate whether participants received cash transfers, and thus we cannot separately

378 determine cash transfer program effects on beneficiaries and non-beneficiaries, our objective was

379 to evaluate the overall population-level effect of these programs, and it is plausible that the

380 effects are larger on beneficiaries relative to non-beneficiaries. While we included country and

381 year fixed effects and used a difference-in-differences design, the possibility of residual

382 confounding related to unmeasured time-varying variables remains, though the robustness of our

383 results after controlling for the available time-varying country-specific variables suggests this

384 bias, if present, is minor. Specifically, there are country-specific policies that influence cash

385 transfer program coverage and uptake (e.g., outreach, enrollment procedures, ease of benefit 
medRxiv preprint doi: https://doi.org/10.1101/2021.12.16.21267921; this version posted December 17, 2021. The copyright holder for this preprint (which was not certified by peer review) is the author/funder, who has granted medRxiv a license to display the preprint in perpetuity.

It is made available under a CC-BY-NC-ND 4.0 International license .

386

387

388

389

390

391

392

393

394

395

396

397

398

399

400

401

402

403

404

405

406

407

408

receipt). We attempted to control for these differences by including country fixed effects and the

World Bank Governance Indicators in regression models, but if these policies differed between

countries over time and were also associated with changes in HIV-related outcomes this may

influence our findings. Importantly, though, we were attempting to examine the effects of cash

transfer programs as they are delivered in the real world and would emphasize that

implementation failures would most likely bias our results towards the null. The study period we

considered was one of generally substantial expansion of HIV control programs, and the

relationship between cash transfer programs and HIV-related outcomes may differ in settings

with already established HIV care systems.

\section{Conclusion}

In this difference-in-differences study of 42 countries with generalized HIV epidemics from

1996 to 2019, we found that cash transfer programs were associated with an immediate reduction

in new HIV infections, a delayed improvement in AIDS-related deaths and the proportion of

people with HIV receiving antiretroviral therapy, a reduction in sexually transmitted infections in

the last 12 months among females, and an increase in recent HIV testing among males and

females. Based on our results, experimental studies that further investigate the effects of unconditional cash transfers on HIV incidence and other HIV prevention behaviors should be a

priority for future research. This study also contributes to our understanding of the social

determinants of health, and suggests that HIV-related benefits should be included in cost-benefit

analyses of cash transfer programs. As countries expand cash transfer programs, particularly in

the context of the COVID-19 pandemic, these findings suggest that anti-poverty interventions

like cash transfers should receive greater attention as part of HIV control efforts, alongside the

already existing focus on expanding biomedical services. 
410 None

\section{Declaration of Interests}

412 The authors declare no conflicts of interest.

\section{Author Contribution Statement}

414 AR and HT conceptualized and designed the study. AR conducted the primary analysis and

415 wrote the first draft of the manuscript, both with critical feedback from HT.

\section{References}

417 1. UNAIDS. UNAIDS Data 2019. http://aidsinfo.unaids.org/ (accessed 1/11/21.

4182 2. UNAIDS. Fast-track: ending the AIDS epidemic by 2030. Geneva: UNAIDS 2014.

419 3. UNAIDS. Social protection: a Fast-Track commitment to end AIDS. Geneva: UNAIDS

4202018.

421 4. Richterman A, Leandre F, Jerome JG, Tsai AC, Ivers LC. Mortality Over Long-term Follow-

422 up for People With HIV Receiving Longitudinal Care and Antiretroviral Therapy in Rural Haiti.

423 Open Forum Infect Dis 2020; 7(8): ofaa328.

$4245 . \quad$ Joint United Nations Programme on HIV/AIDS and STRIVE. Transactional sex and HIV 425 risk: from analysis to action. Geneva, 2018.

426 6. Lopman B, Lewis J, Nyamukapa C, Mushati P, Chandiwana S, Gregson S. HIV incidence 427 and poverty in Manicaland, Zimbabwe: is HIV becoming a disease of the poor? AIDS (London, 428 England) 2007; 21 Suppl 7(Suppl 7): S57-66.

429 7. Brodish PH. An association between neighbourhood wealth inequality and HIV 430 prevalence in sub-Saharan Africa. J Biosoc Sci 2015; 47(3): 311-28.

431 8. Gaumer G, Sherafat-Kazemzadeh R, Jordan M, Nandakumar A. Wealth and wealth 432 inequality in adult HIV prevalence. J Glob Health Rep 2021: e2020105.

433 9. Eaton LA, Cain DN, Pitpitan EV, et al. Exploring the relationships among food insecurity, 434 alcohol use, and sexual risk taking among men and women living in South African townships. J 435 Prim Prev 2014; 35(4): 255-65.

436 10. Singer AW, Weiser SD, McCoy SI. Does Food Insecurity Undermine Adherence to 437 Antiretroviral Therapy? A Systematic Review. AIDS Behav 2015; 19(8): 1510-26. 
438 11. Weiser SD, Tsai AC, Gupta R, et al. Food insecurity is associated with morbidity and patterns of healthcare utilization among HIV-infected individuals in a resource-poor setting. AIDS (London, England) 2012; 26(1): 67-75.

441 12. Aibibula W, Cox J, Hamelin A-M, McLinden T, Klein MB, Brassard P. Association Between 442 Food Insecurity and HIV Viral Suppression: A Systematic Review and Meta-Analysis. AIDS and 443 Behavior 2017; 21(3): 754-65.

444 13. Bastagli F, Hagen-Zanker J, Harman L, Barca V. Cash transfers: what does the evidence say? London: Overseas Development Institute, 2016. 14. Mani A, Mullainathan S, Shafir E, Zhao J. Poverty Impedes Cognitive Function. Science (New York, NY) 2013; 341(6149): 976. 15. Weiser SD, Palar K, Hatcher AM, Young S, Frongillo EA, Laraia B. Food Insecurity and Health: A Conceptual Framework. In: Ivers LC, ed. Food Insecurity and Public Health. Boca Raton, Fla, USA: CRC Press; 2015.

16. Haushofer J, Fehr E. On the psychology of poverty. Science (New York, NY) 2014; 344(6186): 862.

17. Schilbach F, Schofield H, Mullainathan S. The Psychological Lives of the Poor. Am Econ Rev 2016; 106(5): 435-40.

18. Fernald LC, Gertler PJ, Neufeld LM. Role of cash in conditional cash transfer programmes for child health, growth, and development: an analysis of Mexico's Oportunidades. Lancet 2008; 371(9615): 828-37. Development. In: Bundy D, de Silva N, Horton S, Jamison DT, Patton G, eds. Disease Control Priorities. Third edition ed. Washington, DC: World Bank. schooling on prevalence of HIV and herpes simplex type 2 in Malawi: a cluster randomised trial. Lancet 2012; 379(9823): 1320-9. incidence in young women in rural South Africa (HPTN 068): a phase 3, randomised controlled trial. The Lancet Global health 2016; 4(12): e978-e88. Transfer Program Reduces the Risk of Sexual Debut among Young People Age 15-25. PloS one 2014; 9(1): e85473.

\section{Handa S, Angeles G, Abdoulayi S, Mvula P, Tsoka M. Malawi Social Cash Transfer} Program Endline Impact Evaluation Report: University of North Carolina Chapel Hill, 2016. 24. Socialprotection.org Programme Database. https://socialprotection.org/discover/programme (accessed 1/11/21.

$47425 . \quad$ Fahey CA, Njau PF, Katabaro E, et al. Financial incentives to promote retention in care and viral suppression in adults with HIV initiating antiretroviral therapy in Tanzania: a three-arm randomised controlled trial. The Lancet HIV 2020; 7(11): e762-e71.

$47726 . \quad$ Thornton RL. The Demand for, and Impact of, Learning HIV Status. Am Econ Rev 2008;

478 98(5): 1829-63.

479 27. Kohler H-P, Thornton RL. Conditional cash transfers and HIV/AIDS prevention:

480 unconditionally promising? The World Bank Economic Review 2012; 26(2): 165-90. 
481 28. Kim HB, Haile B, Lee T. Promotion and Persistence of HIV Testing and HIV/AIDS

482 Knowledge: Evidence From a Randomized Controlled Trial in Ethiopia. Health Econ 2017;

483 26(11): 1394-411.

484 29. Kranzer K, Simms V, Bandason T, et al. Economic incentives for HIV testing by adolescents in Zimbabwe: a randomised controlled trial. The lancet HIV 2018; 5(2): e79-e86. 30. Yotebieng $\mathrm{M}$, Thirumurthy $\mathrm{H}$, Moracco KE, et al. Conditional Cash Transfers to Increase Retention in PMTCT Care, Antiretroviral Adherence, and Postpartum Virological Suppression: A Randomized Controlled Trial. Journal of acquired immune deficiency syndromes (1999) 2016; 72 Suppl 2(Suppl 2): S124-S9. antiretroviral therapy among HIV-infected adults in Tanzania. AIDS (London, England) 2017; 31(6): 815-25.

32. Emenyonu N, Muyindike W, Habyarimana J, et al. Cash transfers to cover clinic transportation costs improve adherence and retention in care in a HIV treatment program in rural Uganda. 17th conference on retroviruses and opportunistic infections; 2010; 2010. p. 169.

33. Linnemayr S, Stecher C, Mukasa B. Behavioral economic incentives to improve adherence to antiretroviral medication. AIDS (London, England) 2017; 31(5): 719-26. Viral Suppression Among HIV-Positive Patients: A Randomized Clinical Trial (HPTN 065). JAMA Intern Med 2017; 177(8): 1083-92.

35. Thirumurthy $\mathrm{H}$, Ndyabakira A, Marson $\mathrm{K}$, et al. Financial incentives for achieving and maintaining viral suppression among HIV-positive adults in Uganda: a randomised controlled trial. The lancet HIV 2019; 6(3): e155-e63. Improve Linkage to Care and Antiretroviral Therapy Initiation Among HIV-Positive Adults in Cape Town, South Africa. AIDS Patient Care STDS 2018; 32(2): 70-8.

508 37. Metsch LR, Feaster DJ, Gooden L, et al. Effect of Patient Navigation With or Without 509 Financial Incentives on Viral Suppression Among Hospitalized Patients With HIV Infection and Substance Use: A Randomized Clinical Trial. Jama 2016; 316(2): 156-70.

511 38. The World Bank. World Development Indicators. https://data.worldbank.org/data-

512 catalog/world-development-indicators (accessed 1/12/21.

513 39. PEPFAR Panorama Spotlight: Financial Management. https://data.pepfar.gov/financial 514 (accessed 2/11/21.

515 40. TheGlobalFund Data Service. https://data-service.theglobalfund.org/downloads 516 (accessed 1/12/21.

517 41. Goodman-Bacon A. Difference-in-differences with variation in treatment timing. Journal 518 of Econometrics 2021.

519 42. Callaway B, Sant'Anna PHC. Difference-in-Differences with multiple time periods.

520 Journal of Econometrics 2020.

521 43. Jakiela P. Simple Diagnostics for Two-Way Fixed Effects. arXiv preprint arXiv:210313229

$522 \quad 2021$.

523 44. Bendavid E, Bhattacharya J. The President's Emergency Plan for AIDS Relief in Africa: an

524 evaluation of outcomes. Ann Intern Med 2009; 150(10): 688-95. 
525 45. Björkman Nyqvist M, Corno L, De Walque D, Svensson J. Incentivizing safer sexual 526 behavior: evidence from a lottery experiment on HIV prevention. American Economic Journal:

527 Applied Economics 2018; 10(3): 287-314.

528 46. Karim A, Leask K, Kharsany A, al. e. Impact of conditional cash incentives on HSV-2 and 529 HIV prevention in rural South African high school students: results of CAPRISA 007 cluster 530 randomized trial. International AIDS Conference. Vancouver, Canada. TUAC0101LB; 2015. 531 47. de Walque $D$, Dow WH, Nathan $\mathrm{R}$, et al. Incentivising safe sex: a randomised trial of 532 conditional cash transfers for HIV and sexually transmitted infection prevention in rural 533 Tanzania. BMJ Open 2012; 2(1): e000747.

534 48. Cluver L, Boyes M, Orkin M, Pantelic M, Molwena T, Sherr L. Child-focused state cash 535 transfers and adolescent risk of HIV infection in South Africa: a propensity-score-matched case536 control study. The Lancet Global health 2013; 1(6): e362-70. 
Table 1. Characteristics of included countries that implemented a cash transfer program (or combination of programs) with greater

\begin{tabular}{|c|c|c|c|c|}
\hline & $\begin{array}{c}\text { Intervention Countries } \\
\mathbf{N}=\mathbf{2 1}\end{array}$ & $\begin{array}{c}\begin{array}{c}\text { Comparison Countries } \\
\mathrm{N}=21\end{array} \\
\end{array}$ & $\begin{array}{r}\text { Total } \\
\mathrm{N}=42 \\
\end{array}$ & p-value \\
\hline Population (1000s), 1996, median (IQR) & $10,372(2,786-21,032)$ & $4,349(1,663-7,251)$ & $11,801(2,948-25,876)$ & 0.45 \\
\hline Region, $\mathbf{N}(\%)$ & & & & $<.0001$ \\
\hline Africa & $16(76)$ & $20(95)$ & $36(86)$ & \\
\hline Latin America / Caribbean & $3(14)$ & $1(5)$ & $4(10)$ & \\
\hline Asia & $2(10)$ & $0(0)$ & $2(5)$ & \\
\hline \multicolumn{5}{|l|}{ HIV Prevalence, median (IQR) } \\
\hline 1996 & $4.1(2.0-12.5)$ & $1.7(1.4-4)$ & $2.8(1.6-6.3)$ & 0.007 \\
\hline 2005 & $4.4(1.7-12.0)$ & $2.2(1.4-4.0)$ & $2.7(1.4-6.2)$ & 0.02 \\
\hline 2019 & $3.2(1.1-12.1)$ & $2.0(1.3-3.4)$ & $2.4(1.2-6.1)$ & 0.04 \\
\hline \multicolumn{5}{|l|}{ Annual HIV Incidence per 100,000, median (IQR) } \\
\hline 1996 & $379(160-988)$ & $218(128-377)$ & $246(145-484)$ & 0.01 \\
\hline 2005 & $237(77-539)$ & $130(90-209)$ & $153(86-350)$ & 0.06 \\
\hline $\begin{array}{ll}2019 \\
\end{array}$ & $80(26-273)$ & $59(40-106)$ & $66(38-172)$ & 0.32 \\
\hline \multicolumn{5}{|l|}{ Annual AIDS-related Death Rate per 100,000, median (IQR) } \\
\hline 1996 & $137(69-284)$ & $87(45-113)$ & $94(46-193)$ & 0.01 \\
\hline 2005 & $168(83-546)$ & $125(73-147)$ & $132(74-272)$ & 0.02 \\
\hline 2019 & $47(24-95)$ & $38(22-79)$ & $47(22-82)$ & 0.27 \\
\hline \multicolumn{5}{|l|}{ Proportion of population receiving ART, median (IQR) } \\
\hline 2005 & $4(3-7)$ & $2(1-6)$ & $3(2-7)$ & 0.09 \\
\hline 2019 & $74(62-82)$ & $57(43-64)$ & $64(46-79)$ & 0.01 \\
\hline PEPFAR recipient, $\mathbf{N}(\%)$ & $16(76)$ & $8(38)$ & $24(57)$ & 0.03 \\
\hline \multicolumn{5}{|l|}{ PEPFAR funding per capita, median (IQR) } \\
\hline 2005 & $0.0(0.0-2.8)$ & $0.0(0.0-0.7)$ & $0.0(0.0-2.4)$ & 0.57 \\
\hline 2019 & $6.9(0.3-9.2)$ & $0.0(0.0-3.2)$ & $1.0(0.0-8.2)$ & 0.05 \\
\hline HIV Global Fund recipient, $\mathbf{N}(\%)$ & $21(100)$ & $21(100)$ & $42(100)$ & $\mathrm{n} / \mathrm{a}$ \\
\hline \multicolumn{5}{|l|}{ HIV Global Fund disbursements per capita, median (IQR) } \\
\hline 2005 & $0.7(0.2-1.6)$ & $0.7(0.3-1.1)$ & $0.7(0.2-1.6)$ & 0.4 \\
\hline 2019 & $1.4(1.1-3.1)$ & $1.4(0.8-2.0)$ & $1.4(0.8-2.7)$ & 0.13 \\
\hline World Bank Governance Indicators, 1996 & & & & \\
\hline
\end{tabular}




\begin{tabular}{|c|c|c|c|c|}
\hline Corruption, median (IQR) & $-0.7(-1.1-0.1)$ & $-0.6(-0.9--0.1)$ & $-0.7(-1.0-0.0)$ & 0.68 \\
\hline Stability and Violence, median (IQR) & $-0.4(-0.9--0.1)$ & $-0.3(-1.2-0.3)$ & $-0.4(-1.1-0.1)$ & 0.75 \\
\hline Voice and Accountability, median (IQR) & $-0.6(-0.9-0.3)$ & $-0.9(-1.3--0.2)$ & $-0.7(-1.1--0.1)$ & 0.19 \\
\hline Effectiveness, median (IQR) & $-0.7(-1.0--0.2)$ & $-0.7(-1.2--0.2)$ & $-0.7(-1.1--0.2)$ & 0.34 \\
\hline Rule of Law, median (IQR) & $-0.7(-1.0--0.2)$ & $-0.8(-1.3-0.0)$ & $-0.8(-1.3--0.2)$ & 0.56 \\
\hline Regulatory Quality, median (IQR) & $-0.3(-1.0-0.1)$ & $-0.7(-1.3--0.3)$ & $-0.5(-1.1--0.2)$ & 0.21 \\
\hline
\end{tabular}


Table 2. The relationship between cash transfer programs and individual- and country-level HIV-related outcomes.

\begin{tabular}{|c|c|c|c|c|c|c|}
\hline \multirow[t]{2}{*}{ Outcomes } & \multicolumn{2}{|c|}{ Cash Transfer Program } & \multicolumn{2}{|c|}{$\begin{array}{l}\text { PEPFAR Funding per } \\
\text { capita (per } \$ 5 \text { increase) }\end{array}$} & \multicolumn{2}{|c|}{$\begin{array}{l}\text { HIV-related Global Fund } \\
\text { Disbursements per capita } \\
\quad \text { (per } \$ 5 \text { increase) }\end{array}$} \\
\hline & $\begin{array}{c}\text { Effect } \\
\text { Measure }\end{array}$ & $95 \% \mathrm{CI}$ & $\begin{array}{c}\text { Effect } \\
\text { Measure }\end{array}$ & $95 \% \mathrm{CI}$ & $\begin{array}{c}\text { Effect } \\
\text { Measure }\end{array}$ & $95 \% \mathrm{CI}$ \\
\hline \multicolumn{7}{|c|}{ Individual-level, Females } \\
\hline Age at sexual debut among youths, coefficient ${ }^{\top}$ & 0.00 & $-0.09-0.10$ & 0.03 & $-0.01-0.07$ & 0.01 & $-0.09-0.12$ \\
\hline Sexually transmitted infection within 12 months, odds ratio ${ }^{1}$ & 0.67 & $0.50-0.91$ & 0.98 & $0.80-1.19$ & 0.90 & $0.74-1.09$ \\
\hline Greater than 1 sexual partner within 12 months, odds ratio ${ }^{1}$ & 1.04 & $0.75-1.46$ & 1.17 & $0.89-1.54$ & 0.88 & $0.67-1.15$ \\
\hline HIV test within 12 months, odds ratio ${ }^{1}$ & 2.61 & $1.15-5.88$ & 1.14 & $1.01-1.30$ & 1.48 & $1.18-1.84$ \\
\hline Condom use at last sex, odds ratio ${ }^{1}$ & 0.94 & $0.77-1.14$ & 1.01 & $0.91-1.09$ & 1.16 & $0.99-1.37$ \\
\hline \multicolumn{7}{|c|}{ Individual-level, Males } \\
\hline Age at sexual debut among youths, coefficient ${ }^{\top}$ & -0.14 & $-0.28-0.01$ & 0.04 & $-0.04-0.11$ & -0.023 & $-0.16-0.12$ \\
\hline Sexually transmitted infection within 12 months, odds ratio ${ }^{1}$ & 1.10 & $0.85-1.43$ & 1.01 & $0.90-1.13$ & 1.02 & $0.80-1.31$ \\
\hline Greater than 1 sexual partner within 12 months, odds ratio ${ }^{1}$ & 1.12 & $0.99-1.28$ & 1.02 & $0.91-1.13$ & 1.00 & $0.91-1.09$ \\
\hline HIV test within 12 months, odds ratio ${ }^{1}$ & 3.19 & $2.45-4.15$ & 1.22 & $1.12-1.32$ & 1.22 & $1.09-1.36$ \\
\hline Condom use at last sex, odds ratio ${ }^{1}$ & 0.88 & $0.75-1.04$ & 1.02 & $0.96-1.07$ & 1.00 & $0.89-1.14$ \\
\hline Transactional sex within 12 months, odds ratio $^{1}$ & 0.99 & $0.85-1.15$ & 0.93 & $0.80-1.09$ & 1.07 & $0.88-1.31$ \\
\hline \multicolumn{7}{|c|}{ Country-level } \\
\hline New HIV infections, incidence rate ratio ${ }^{2}$ & 0.94 & $0.89-0.99$ & 1.00 & $0.99-1.01$ & 0.99 & $0.98-1.00$ \\
\hline AIDS-related deaths, incidence rate ratio ${ }^{2}$ & 0.99 & $0.95-1.03$ & 0.98 & $0.97-0.99$ & 0.99 & $0.98-1.01$ \\
\hline Proportion of people with HIV receiving ART, coefficient ${ }^{2}$ & 5.0 & $-0.2-10.1$ & 2.6 & $1.7-3.5$ & 3.3 & $0.4-6.2$ \\
\hline
\end{tabular}

${ }^{1}$ Multivariable models include cash transfer program, age, single marital status, education, wealth quintile, rural household setting, 543 and the country-level covariates GDP per capita, PEPFAR funding per capita, HIV-related Global Fund disbursements per capita, and 544 three World Bank Governance Indicators: Corruption, Stability and Violence, and Voice and Accountability. 
$545{ }^{2}$ Multivariable models include the country-level covariates GDP per capita, PEPFAR funding per capita, HIV-related Global Fund

546 disbursements per capita, and three World Bank Governance Indicators: Corruption, Stability and Violence, and Voice and

547 Accountability. 
549 Figure 1 - Proposed causal framework with directed acyclic graph (DAG) outlining potential relationships between large-scale cash

550 transfer programs and HIV-related outcomes, mediated through an anti-poverty effect. The green box is the exposure of interest (cash

551 transfer programs). The blue boxes are the HIV-related outcomes of interest, two more proximal (sex behaviors, HIV treatment

552 cascade) and two more distal (HIV incidence, AIDS-related deaths). The orange boxes are ancestors of both the exposure and the

553 outcomes (i.e., confounders). Underneath each box are the covariates used to measure the constructs within the boxes. Covariates from

554 the DHS are individual-level, and all other covariates are country-level.

555 Figure 2 - Timeline of included countries, with the green line indicating the cash transfer period, and the colored dots indicating years 556 during which a Demographic and Health Survey (DHS) was conducted.

557 Figure 3 - Adjusted incidence rate ratios of new HIV infections and AIDS-related deaths, and adjusted change in the proportion of

558 proportion of people with HIV receiving antiretroviral therapy, as a function of year of the cash transfer period.

559 Figure 4 - Interaction analysis of baseline HIV prevalence at the start of the cash transfer period (above or below the median, $3.7 \%$ )

560 and impoverished population coverage of the cash transfer program(s) (above or below the median, 23\%) for individual- (stratified by

561 sex) and country-level outcomes, with adjusted odds ratios for individual-level outcomes and adjusted incidence rate ratios for

562 country-level outcomes, and p-values for interaction. 


\section{Time-varying}

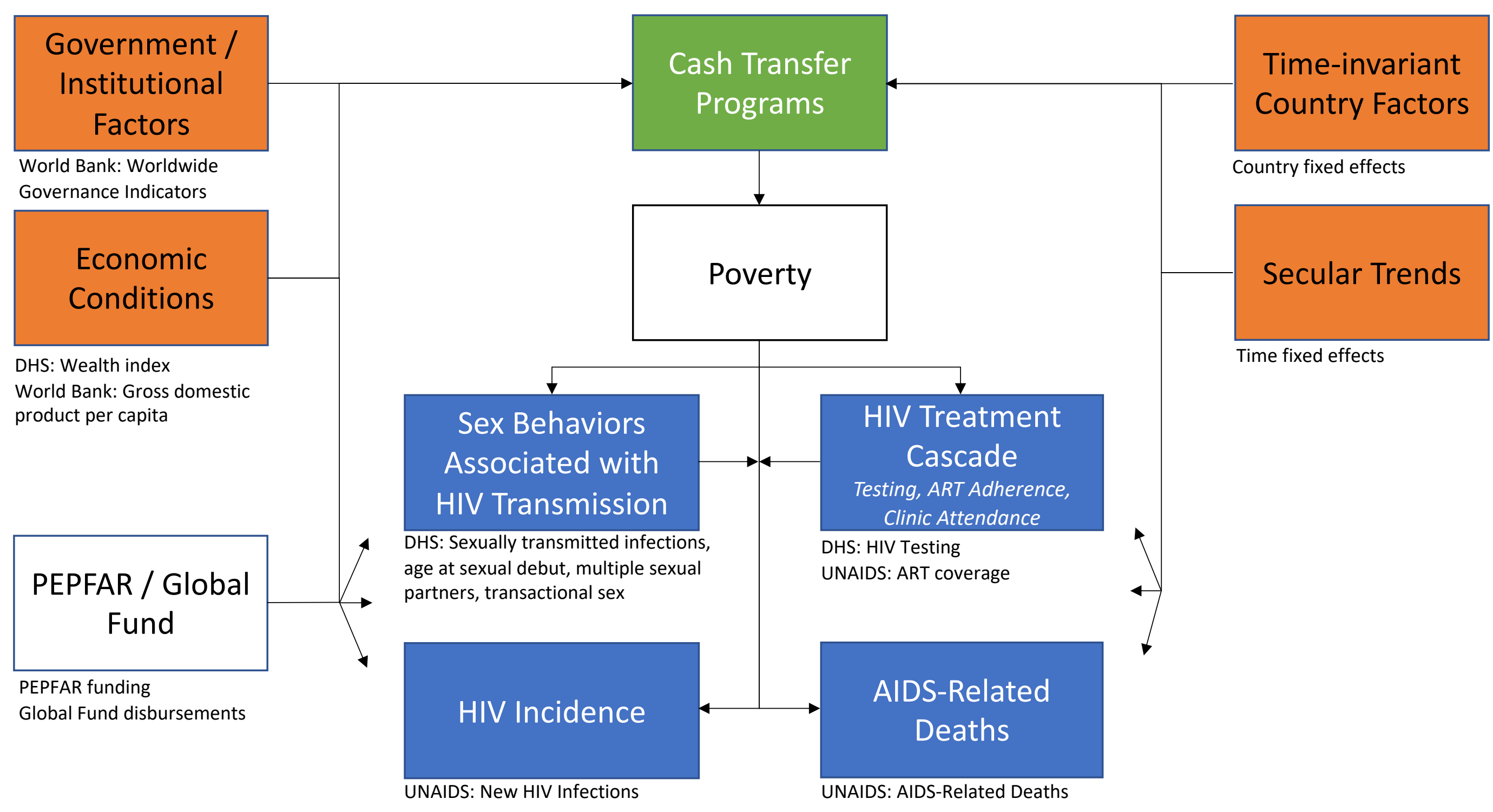




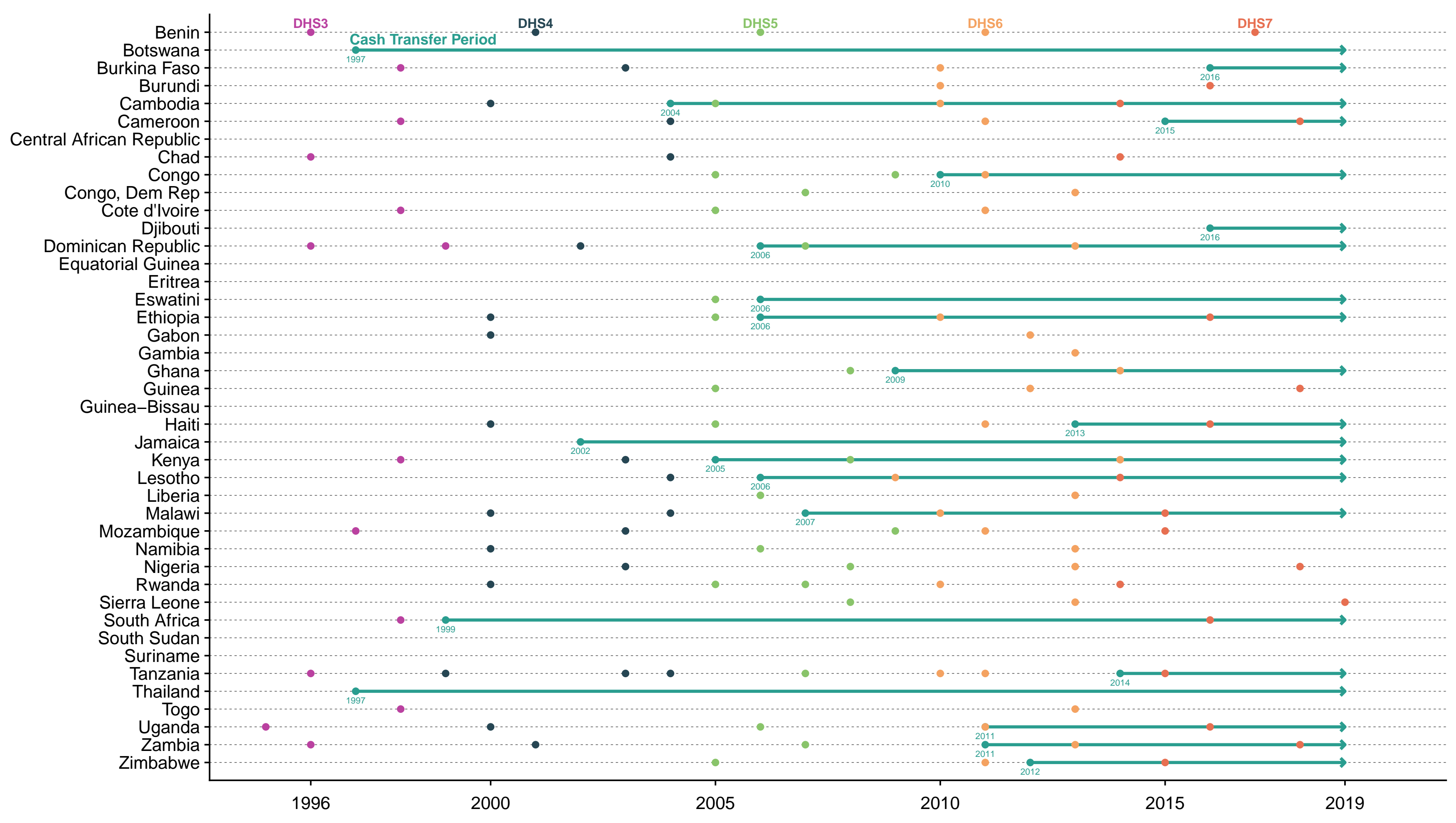


medRxiv preprint doi: https://doi.org/10.1101/2021.12.16.21267921; this version posted December 17, 2021. The copyright holder for this preprint (which was not certified by peer review) is the author/funder, who has granted medRxiv a license to display the preprint in perpetuity.

Females

It is made available under a CC-BY-NC-ND 4.0 International license .

$P$ for interaction

STI in last 12 months
High prevalence
Low prevalence
High coverage
Low coverage
High prevalence
Low coverage
Multiple sex partners in last 12 months
High prevalence
Low prevalence
Low coverage
Condom use at last sex
High prevalence
Low prevalence
High coverage
Low coverage

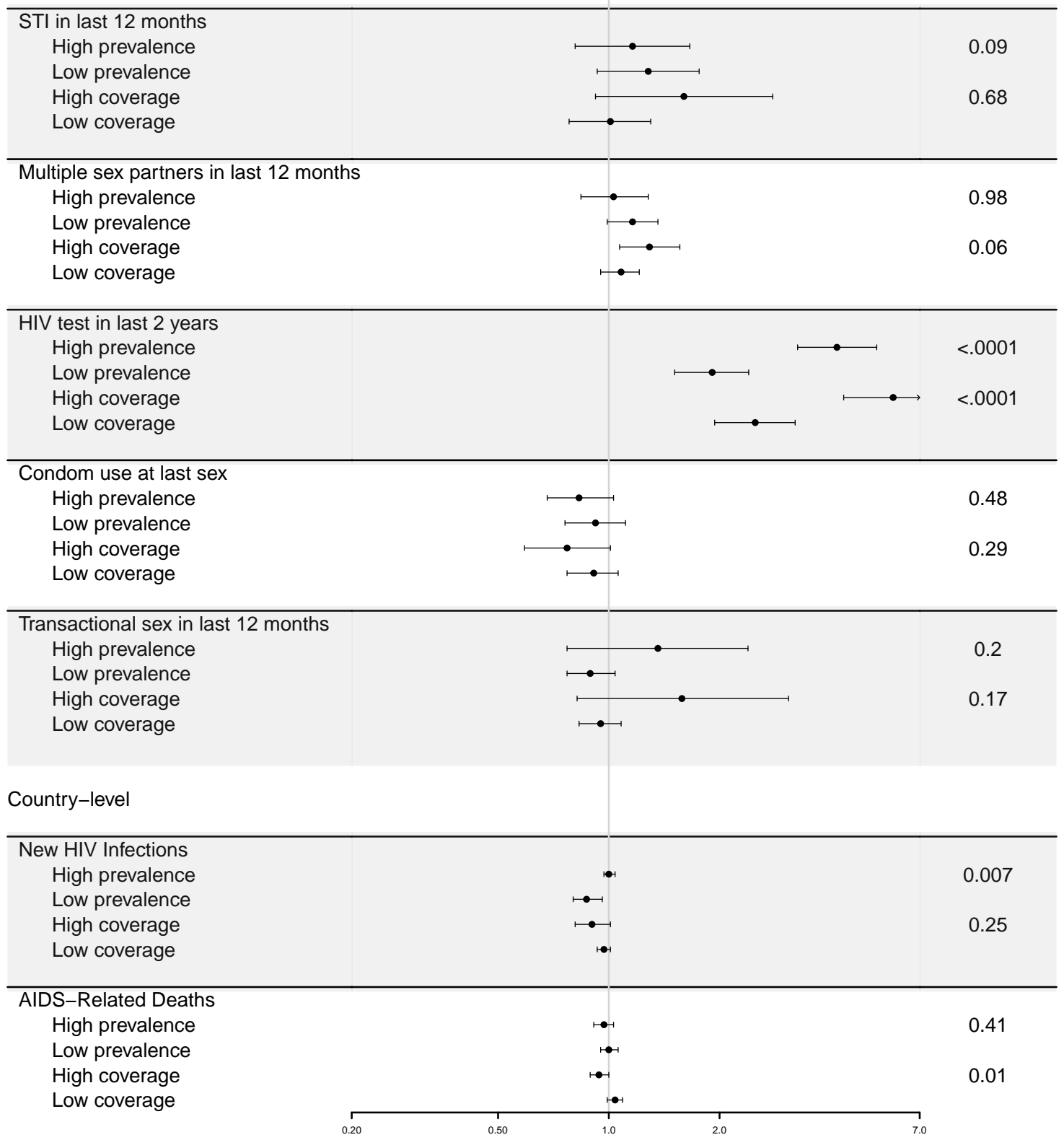

